\title{
Response of Alpine Grassland Vegetation Phenology to Snow Accumulation and Melt in Namco Basin
}

\author{
Siyu Chen ${ }^{1,2}$, Xia Cui ${ }^{3}$, Tiangang Liang ${ }^{4}$ \\ ${ }^{1 .}$ National Administration of Surveying, Mapping and Geoinformation engineering research center of Geographic National \\ Conditions Monitoring, Xian 710000, China - chensiyu1106@gmail.com \\ 2. The First Institute of Photogrammetry and Remote Sensing, Xian 710000, China \\ ${ }^{3}$ Key Laboratory of Western China's Environmental Systems(Ministry of Education),College of Earth and Environmental Sciences, \\ Lanzhou University, Lanzhou 730010, China - 5294925@qq.com \\ 4. College of Pastoral Agriculture Science and Technology, Lanzhou University, Lanzhou 730010, China - tgliang@1zu.edu.cn
}

KEY WORDS: Vegetation Greening, Vegetation Growth Length, Snow Cover Fraction, Trend Analysis, Relationship, Namco Basin

\begin{abstract}
:
Snow/ice accumulation and melt, as a vital part of hydrological processes, is close related with vegetation activities. Taking Namco basin for example, based on multisource remote sensing data and the ground observation data of temperature and precipitation, phenological information was extracted by S-G filtering and dynamic threshold method. Daily snow cover fraction was calculated with daily cloud-free snow cover maps. Evolution characteristics of grassland vegetation greening, growth length and daily snow cover fraction and their relationship were analyzed from 2001 to 2013. The results showed that most of grassland vegetation had advanced greening and prolong growth length trend in Namco basin. There were negative correlations between snow cover fraction and vegetation greening or growth length. The response of vegetation phenology to snow cover fraction is more sensitive than that to temperature in spring. Meanwhile, vegetation growth condition turned worse with advanced greening and prolong growth length. To a certain extent, our research reveals the relationship between grassland vegetation growth cycle and snow in alpine ecosystem. It has provided reference to research the response mechanism of alpine grassland ecosystem to climate changes.
\end{abstract}

\section{INTRODUCTION}

In past 100 years, it is well-know that global climate continued to warming (Leo and IPCC, 2015). Due to warmer climate, the starting time of snow melt is earlier than it did before. Snow/ice accumulation and melt, as a vital part of hydrological processes, which is close related with vegetation activities and ecosystem functioning (Barnett, et al., 2005). Especially, with the increasing temperature and earlier snow melt, the phenology of alpine grassland vegetation is strongly influenced in snow-dominated basins. Thus, studying response of spring phenology to snow accumulation and melt in snow-dominated basins can help to further understand the climate driving force to impacts in hydrological cycle in regional scale and vegetation activity.

According to recent literatures, variation in snowmelt or snow duration can affect lots of factors in alpine ecosystem, including changes 1) in water fluxes, hydrological cycle and evaporation related to vegetation growth; 2) in species composition, community structure and pests or pathogens; 3 ) in time of soil nutrient availability and indispensable moisture condition (Cornelius, et al., 2013; Saccone, et al., 2013; Dunn, et al., 2007; Schimel \& Bennett, 2004; Keller \& Körner, 2003; Wielgolaski \& Inouye, 2003). Several studies 
in different region showed that different response of vegetation activity to snow melt advancement or delay, and duration and so on (Julitta, et al., 2013; Buus-Hinkler, et al., 2006). For example, Cornelius et al. (2013) indicated that changes in the date of snowmelt because of global warming may affect more species at higher altitudes than that at lower altitudes. Some author analyzed the linkage between snow cover and vegetation activities based on remote sensing data and digital camera. Buus-Hinkler et al. (2006) indicated that in some Arctic regions increasing snow cover duration or depth in winter might be even more crucial than the increasing temperature for the ecosystem. Julitta et al. (2013) found that snowmelt dates were quite unexpectedly negatively related to the beginning of the growing season in the Italian Alps. There were many studies focusing on study the interaction mechanism between snow and vegetation. However, their results were very different due to different study area with different geographic factors and regional scales, such as latitude, elevation and terrain.

Namco basin has a unique geographical environment, with a highest lake and glaciers and perennial snow cover. Other studies have shown that the melt water from snow cover and glaciers is one of main resource of Lake Namco water increasing (Chen et al., 2009; Wu et al., 2008; Zhang et al., 2014; Zhu et al., 2006). Thus, it is necessary to discuss two problems as follows: 1) what are the trends of snow cover accumulation to melting in Namco basin in recent year? 2) How does the spatial pattern of phenology change in response to an exceptionally early snowmelt year?

The objective of this study is: 1) to calculate snow cover, vegetation phenology and temperature maps in Namco basin, which is based on multi-source remote sensing data; 2) to discuss and evaluate their spatial patterns and interrelationships. It is anticipated that this study would provide a scientific basis for evaluation of vegetation phenology and land surface hydrologic cycle.

\section{STUDY AREA}

Lake Namco is the highest lake in the world, as well as the third largest salty lake in China. Namco basin, an area of $10,610 \mathrm{~km} 2$ (between $30^{\circ} 30^{\prime}$ to $30^{\circ} 56^{\prime} \mathrm{N}$ and $90^{\circ} 16^{\prime}$ to $91^{\circ} 03^{\prime}$ E), is an enclosed basin with the average altitude of $5019 \mathrm{~m}$ in north of Gangdise and Nyainqentanglha mountains and belongs to basins of southern Qiangtang plateau in North Tibet. The average altitude of Nyainqentanglha Mountains is $5500 \mathrm{~m}$, with the highest peak of $7162 \mathrm{~m}$. The Nyainqentanglha Mountains have many glaciers, with melt water from the glaciers directly flowing into the basin and the lake. The north and northwest parts of the basin consist of a gently undulating, low-mountainous area. The basin is less affected by the human being, and evaluation of snow and ice and grassland in the basin is mainly controlled by natural condition and climate changes. With longer winter duration and heavy snow, the mainly grassland type of basin is alpine meadow which has strong environmental heterogeneity and rich biodiversity (Bolch, et al., 2010; Wu et al., 2008).

\section{MATERIALS AND METHODOLOGIES}

\subsection{Meteorological Dataset}

In this study, climate records from two meteorological stations (i.e., Bangoin and Xainza stations), closest to the Nam Co basin, are used. These data include daily mean, maximum, and minimum temperatures, and daily precipitation from 2001 to 2010

\subsection{Extracting vegetation phenological information}

The 16-days vegetation index products of MOD13A1 from 2001 to 2013 are downloaded, and re-projected into Albers projection with WGS1984 spheroid and resampled pixel size to 500. The EVIs from MOD13A1 are used to reflect the grassland vegetation phenological information. The land cover type products of MCD12Q1 with 500-m spatial resolution are used to determine the area of grassland in the Nam Co basin from 2001 to 2013 .

SG filtering, using local fitting as a main method, can describe subtle feature and changes of EVI data accurately. We rebuild EVIs' curve on the basis of SG filtering. As weighted moving average filter, SG filtering was proposed by Savizky and Golay in 1964 and calculated by $\operatorname{Eq}(1)$.

$$
\operatorname{NDVI}(\mathrm{t})=\frac{\sum_{i=-m}^{i=m} C_{i} N D V I_{j+i}}{N}
$$

We extract grassland vegetation phenological information using dynamic threshold method from Jönsson and Eklundh 
(2004). Due to low grassland vegetation coverage, EVI value is only about 0.3 in exuberance period. Therefore, we extract phenology information in Namco basin from 2001 to 2003 through setting $10 \%$ as the thresholds of vegetation greening and browning, respectively.

\subsection{Daily cloud-free Snow Covered Maps}

MOD10A1 and MYD10A1 during 2001-2013 and Interactive Multi-sensor snow and ice mapping System ( IMS ) snow-covered products during 2002-2013 are used in this study. IMS product, with a spatial resolution of $4 \mathrm{~km}$, is a northern hemisphere snow-covered product which integrates and assimilates the multi-source remote sensing data, the ground observation data, high resolution and airborne observation data. Based on above datasets and a new algorithm (Huang et al., 2012), we derived daily cloud-free snow-covered maps and snow cover fraction in Namco basin during 2003-2013. In addition, the 8-day cloud-removed products were derived during 2001-2002 on the basis of 8-day composition method and MOD10A1 data, with lacking the IMS and MYD10A1 data during 2001-2002.

\subsection{Trend analysis of vegetation phenology}

A linear regression analysis approach from is Stow et al. (2003) used to obtain the trend (S) of the vegetation phenology and identify long term changes during 2001 to 2013.

\subsection{Comparison of the phenological information and the} snow covered fraction

We analyze the relationship between snow and vegetation greening and the growing season length, which SCD using month as a basic unit and according 5 (1 to 5 month) time scales and 5 lag phases. The correlation coefficient between snow cover fraction and greening are calculated under two cases: the same month VS singe month before (1, 2, 3 and 4 month before), and the same month VS month combination (0 before $\sim 1,0 \sim 2,0 \sim 3,0 \sim 4,1 \sim 2,1 \sim 3,1 \sim 4,2 \sim 3,2 \sim 4$ and $3 \sim 4$ months). Then the maximum correlation coefficient are used to present the correlation between greening period and snow cover.

In addition, previous studies have shown that snow changes in snow season period were closely related to the growing season length of grassland vegetation and vegetation growth condition in exuberant period (i.e., Aug). Using 8 time scales (i.e., Jan to Aug) and 8 lag phrases (i.e., before zero to seven month), the average FSC of different time scales is made 36 types of combination which is analyzed and discussed relationship between snow and vegetation growth season. The analysis method is in line with the above, so that won't be covered again here.

\begin{tabular}{|c|c|c|c|c|c|c|c|}
\hline 1 & 2 & 3 & 4 & 5 & 6 & 7 & 8 \\
\hline 0 & $0 \sim 1$ & $0 \sim 2$ & $0 \sim 3$ & $0 \sim 4$ & $0 \sim 5$ & $0 \sim 6$ & $0 \sim 7$ \\
1 & $1 \sim 2$ & $1 \sim 3$ & $1 \sim 4$ & $1 \sim 5$ & $1 \sim 6$ & $1 \sim 7$ & \\
2 & $2 \sim 3$ & $2 \sim 4$ & $2 \sim 5$ & $2 \sim 6$ & $2 \sim 7$ & & \\
3 & $3 \sim 4$ & $3 \sim 5$ & $3 \sim 6$ & $3 \sim 7$ & & & \\
4 & $4 \sim 5$ & $4 \sim 6$ & $4 \sim 7$ & & & & \\
5 & $5 \sim 6$ & $5 \sim 7$ & & & & & \\
6 & $6 \sim 7$ & & & & & & \\
7 & & & & & & & \\
\hline
\end{tabular}

Table 1 the time combination of phenology and snow cover fraction

\section{RESULTS}

\section{1 changes in spatial distribution of vegetation phenology}

Figure 1 shows the changes in grassland vegetation greening and the growth season length which have strongly spatial distribution characteristic in Namco from 2001 to 2013. Over the past 13 years, vegetation greening has advanced in most region. Greening rate of grassland vegetation (<-1 days/year) in the district extended from lake to southwestern and the western of basin is greater than other regions, with the pixels of $54.3 \%$ of rate being smaller than -1 days/year and pixels of $35.7 \%$ of rate between -1 and 0 , respectively. Compared with other regions, the runoffs, such as Bo Qu, Zuo Quka, Ang Qu, Ce Qu and $\mathrm{Gu} \mathrm{Qu}$, provide necessary water for vegetation greening across the district extended from lake to southwestern and the western of basin. As a result, grassland vegetation greening is advanced obviously. It can be seen from figure 1 (b) that the growth period of vegetation in northern, southwestern, and western part of basin is gradually shortened, with the pixels of $44.5 \%$ of rate being smaller than -1 days/year. Meanwhile, region with prolong growth seasons accounted for $55.5 \%$ of pixels. Compared with figure 1 (a) and (b), there has been good spatial consistency between the region with longer growth 
seasons and advanced greening, or between the region with shortened growth seasons and delayed greening. It is indicated that the greening is an important index affecting the growth season length, i.e., the earlier greening with the longer growth season, the later greening with shortened growth season. In a word, over $50 \%$ of grassland vegetation has the trend with advanced greening and longer growth season in the past 13 years in Namco basin.

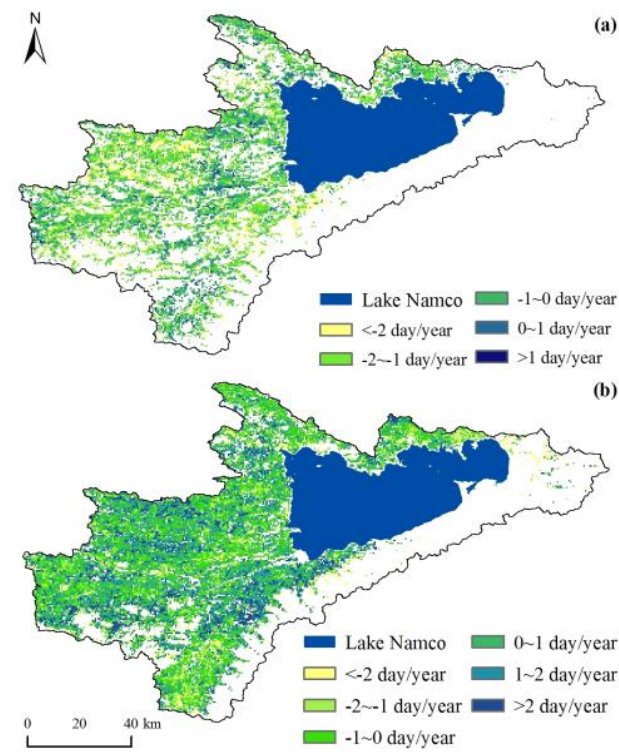

Figure 1 Changes in grassland vegetation greening and growth length from 2001 to 2013

\subsection{Daily snow cover fraction and phenology of alpine grassland in Namco basin}

Figure2 shows changes in snow cover fraction and EVI of grassland vegetation in Namco basin from HY2001 to 2013. Maximum value of snow cover fraction during January to June from 2001 to 2013 is in year of 2007, with the value over than $81.25 \%$. Over than $70 \%$ of snow cover fraction value during 2004 and 2006, 2011 and 2013 is all greater than that of the year of 2001-2003 and 2009. In general, the average snow cover fraction during Jan. to Aug. from 2001 to 2013 shows a decreasing trend year by year with reducing rate of 0.0043 /year (not shown). The date of maximum EVI value showing in years of 2006 and 2014 (both in early July) are earlier than other years, and those in years of 2003, 2007 and 2010 are later than other years (both in early August).

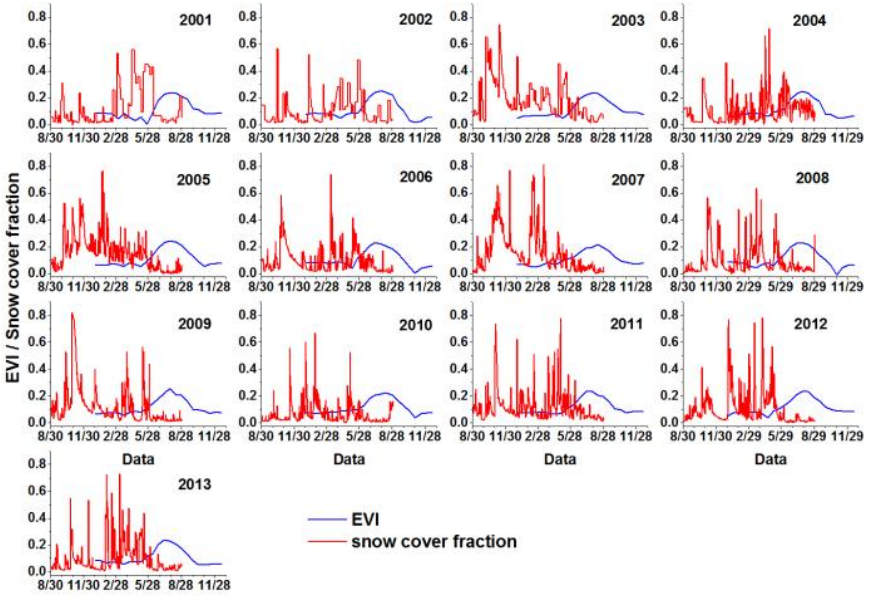

Figure 2 Snow cover fraction and EVI curve in the period of

HY2001-2013

\subsection{Relationship between the snow cover and the vegetation phenology and its response to the time}

Figure 3 shows that SCF and the vegetation greening have a negative correlation, which indicate that the vegetation greening is earlier with smaller SCF value. Through response analysis of the vegetation greening to snow covered days, we find that the correlations between vegetation greening date and mean SCFs with combination month of Apr. and May, or Mar. and May are both higher than that in April or May. The determination coefficients between vegetation greening date and SCFs from Apr. to May, or from Mar. to May, or in April and May are $0.53(\mathrm{P}=0.005), 0.52(\mathrm{P}=0.006), 0.42(\mathrm{P}=0.016)$ and 0.45 , respectively. It can be seen that the highest coefficient is between the vegetation greening and SCF before 0 1 month, and followed by that before 0 2 month. Through analyzing the correlation between grassland vegetation growth length and SCF, we find that there are negative relationship between grassland growth length and SCF by indicating the less grassland growth length with the smaller SCF (Figure 4). Figure $4 \mathrm{~b}$ shows that the SCFs with the single May or combination of Apr. and May are better than other time scale SCFs, with 0.5 and 0.55 of determination coefficients. As a result, not only grassland vegetation greening but also vegetation growth length is influenced by snow. 


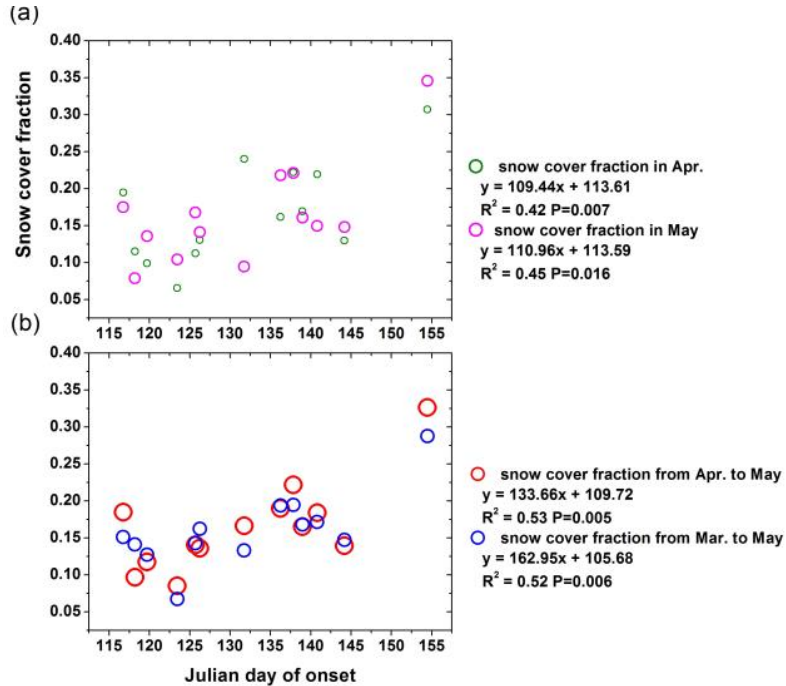

Figure 3 Relationship between snow cover fraction and vegetation greening

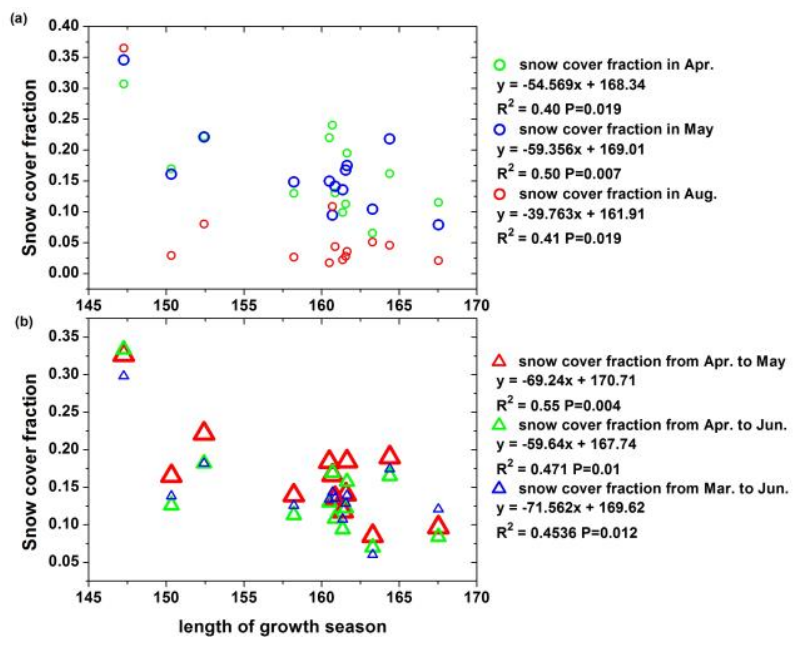

Figure 4 Relationship between snow cover fraction and grassland growth length

In order to further explore the relationship between snow and vegetation, we have analyzed the relationship between spring temperature (i.e., mean temperature from Mar. to May), snow and grassland vegetation greening or growth length in recently 10 years (i.e., from 2001 to 2010). Table 2 shows the correlation coefficients of $0.68(\mathrm{P}=0.031)$ between spring temperature and grassland vegetation greening, 0.55( $\mathrm{P}=0.098)$ between spring temperature and grassland growth length, 0.85( $\mathrm{P}=0.002)$ between mean SCF from Apr. to May and grassland vegetation greening, $0.86(\mathrm{P}=0.003)$ between mean SCF from Apr. to May and grassland growth length, respectively.
We further analysed partial correlation between vegetation phenology and mean SCF from Apr. to May, or spring temperature. Taking mean SCF from Apr. to May as the control factor, the partial correlation coefficients between spring temperature and vegetation greening, or growth length are $0.221(\mathrm{P}=0.567)$ and $0.126(\mathrm{P}=0.747)$. It has been indicated that there is no significant relationship between spring temperature and vegetation phenology without considering influence of snow to vegetation phenology. On the contrary, taking spring temperature as the control factor, the partial correlation coefficients between mean SCF from Apr. to May and vegetation greening, or growth length are 0.725 and 0.794 , with 95\% confidence value of both. It explains that there is a remarkable correlation between snow and vegetation phenology. In summary, results of partial correlation analysis reveal that vegetation phenology is influenced by mean SCF from Apr. to May, however, response of phenology to spring temperature is not obvious.

\begin{tabular}{|c|c|c|c|}
\hline & & $\begin{array}{l}\text { Vegetation } \\
\text { greening }\end{array}$ & Growth length \\
\hline $\begin{array}{l}\text { correlation } \\
\text { coefficient }\end{array}$ & $\begin{array}{l}\text { Spring } \\
\text { temperature } \\
\text { Snow cover } \\
\text { fraction from Apr. } \\
\text { to May }\end{array}$ & $\begin{array}{l}0.68 \\
(\mathrm{P}=0.031) \\
0.85 \\
(\mathrm{P}=0.002)\end{array}$ & $0.55(\mathrm{P}=0.098)$ \\
\hline $\begin{array}{l}\text { partial } \\
\text { correlation } \\
\text { coefficient }\end{array}$ & $\begin{array}{l}\text { Spring } \\
\text { temperature } \\
\text { Snow cover } \\
\text { fraction from Apr. } \\
\text { to May }\end{array}$ & $\begin{array}{l}0.221 \\
(\mathrm{P}=0.567) \\
0.725 \\
(\mathrm{P}=0.027)\end{array}$ & $\begin{array}{l}0.126 \\
(\mathrm{P}=0.747) \\
0.794 \\
(\mathrm{P}=0.011)\end{array}$ \\
\hline
\end{tabular}

Table 2 Analysis of relationship between vegetation phenology and temperature and snow cover fraction

\section{DISCUSSION}

Result from Chen et al. (2014) showed that snow melted water is not only the vital water resource of lake expansion, but also the reason of grassland vegetation turning worse year by year. However, what is the influence of snow on vegetation growth? What is the response mechanism of grassland vegetation to snow ablation process? There are lack of explanation for these question in this article. So we explore 
relationship among snow, vegetation phenology, as well as the influence of snow ablation to vegetation phenology.

We used ratio threshold method (i.e., dynamic threshold method) from Jönsson and Eklundh (2004) to extract vegetation phenology in this study. However, there are lots of extraction methods of vegetation phenology based on remote sensing data currently. Through analysis of five models of extracting vegetation greening, Cong et al. (2012) think that it is necessary to select different phenology extraction model according to the characteristic of study area. In five models, HANTS transform method may estimate vegetation greening early. Vegetation greening using Gauss model is later than the actual greening date. Wang et al. find that Midpoint method is more suitable for the study changes in vegetation greening of temperate monsoon region of China. It is seen that extraction of phenology based on different methods have spatial consistent trend, but the specific time of vegetation phenology have an obvious difference. Based on the study result from Song et al. (2011), it has certain reliability to selected ratio threshold method for extraction of phenology.

In addition, it is difficult to extract and express the specific snow melting time in Namco basin. The snow melting curve is not ideal continuous and smooth. Considering above factors due to a complex snow cover condition, we explore the correlation between vegetation and snow cover using average SCF, and find lower average SCF value during April to May with vegetation greening early. Vegetation greening period is during April and May. With decrease snow cover, snow melted water increase will promote seed germination to help vegetation greening and growth length prolonging. The study result from Buus-Hinkler et al. (2006) shows that snow melted beginning has positive correlation with vegetation greening, as well as a negative correlation between snow ablation length and vegetation growth length under the polar ecosystem. It is indicated that the earlier snow melted and shorten ablation length are important conditions of the vegetation greening. Julitta et al. and Keller and Körner indicate that it is sensitive response of herbage to snow melting, which is an important factor leading to vegetation greening advanced. The results from above studies are consistent with ours.
Our result of partial correlation analysis (Table2) shows a significant response of phenology to snow, but less remarkable response of phenology to spring temperature. This result is consistent with the study of Buus-Hinkler (2006). Thus it can be seen that snow melted water is not only the main water resource of lake volume, but also influence vegetation growth and development. Meanwhile, obvious increasing spring temperature in Namco basin directly accelerates snow melt and vegetation greening advanced. However, there is a significant negative correlation between grassland vegetation growth season and annual maximum EVI value in Namco basin. It is indicated that the grassland growth condition turns worse with prolonged growth length. This result is consistent with the study from Zhang et al. (2013). The reason is the vegetation premature exposure in lower temperature environment with shallow depth snow earlier ablation cause frost damage (Wipf et al., 2006). The result from Inouye (2008) illustrates that bud and flower of herbaceous perennid which is sensitive to frost may increase an odd of frost damage because of advanced ablation season in grassland ecosystem of the Rocky Mountains. Numerous studies have confirmed that vegetation could be obtained good protection by depth snow buried due to later ablation in depth snow covered region. Although this directly leads to vegetation with delay greening and shorten growth length, the time of snow melt is in the period of spring and summer transition, which is provided good hydrothermal conditions to vegetation growth.

Research of relationship between snow and vegetation growth has important significance in discussing the influence of global climate changes to ecosystem. So far, a lot of research on snow and vegetation growth have been done by scholars at home and abroad. However, most of research are mainly in polar ecosystems or alpine region with a continuous snowfall. Our study has a high consistent with previous study, but the relationship between snow cover and vegetation growth in Tibetan Plateau is much more complicated than that in the polar ecosystem and alpine region with a continuous snowfall. Firstly, it is difficult to analyze the response of grassland vegetation phenology to snow in the region with complex terrain due to limitation of low resolution from remote sensing data used in this study. Secondly, shallow depth snow and small area snow exist in Tibet Plateau, with a discontinuous and unsmooth melting curve. Lastly, snow melted water is the 
main water resource of vegetation growth in Tibet Plateau during the dry season. Take Namco basin for example, our study explore initially the relationship between snow cover and vegetation growth in Tibetan Plateau. In future, we need more in-depth studies for predicting the changes in vegetation phenology in coming year through the law of snow accumulation and melting, and its response mechanism.

\section{CONCLUSION}

Taking Namco basin for example, based on multisource remote sensing data and the ground observation data of temperature and precipitation, our study examines the relationship between snow cover and grassland vegetation greening. The following primary conclusions have been reached.

(1) Grassland vegetation greening has advanced trend in most region of Namco Basin from 2001 to 2013. Growth period of vegetation in northern, southwestern, and western part of basin is gradually shortened. Maximum value of snow cover fraction during January to June from 2001 to 2013 is in year of 2007. Over than $70 \%$ of snow cover fraction value during 2004 and 2006, 2011 and 2013 is all greater than that of the year of 2001-2003 and 2009.

(2) SCF and the vegetation greening have a negative correlation. The less grassland growth length with the smaller SCF shows that snow melted water is not only the main water resource of lake volume, but also influence vegetation growth and development. Obvious increasing spring temperature in Namco basin directly accelerates snow melt and vegetation greening advanced. However, the vegetation premature exposure in lower temperature environment will be caused by frost damage because of shallow depth snow earlier ablation.

(3) Our study preliminarily explained the effect of the snow melting process on vegetation growth on the basis of previous studies. However, there are complex relationship between snow cover fraction and vegetation. Qualitative analysis the relationship between snow and vegetation phenology is far from fully explaining the interaction mechanism between them, and further research will be needed in the future.

\section{ACKNOWLEDGEMENTS}

This work was supported by the National Natural Science Foundation of China (41401472).

\section{REFERENCES}

Barnett, T., Adam, J., and Lettenmaier, D., 2005. Potential impacts of a warming climate on water availability in snow-dominated regions. Nature, 438(7066), pp.303-309.

Bolch, T., Yao, T., Kang, S., et al., 2010. A glacier inventory for the western Nyainqentanglha Range and the Nam Co Basin, Tibet, and glacier changes 1976-2009. The Cryosphere, 4(3), pp.419-433.

Buus-Hinkler, J., Hansen, B., Tamstorf, M., et al., 2006. Snow-vegetation relations in a High Arctic ecosystem: Inter-annual variability inferred from new monitoring and modeling concepts. Remote Sensing of Environment, 105(3), pp.237-247.

Chen, F., Kang, S., Zhang, S., et al., 2009. Glaciers and lake change in response to climate change in the Nam Co basin. Mountain Research [In Chinese], 27(6), pp.641-647.

Chen, S., Liang, T., Xie, H., et al., 2014. Interrelation among climate factors, snow cover, grassland vegetation, and lake in the Nam Co basin of the Tibetan Plateau. Journal of Applied Remote Sensing, 8(1), pp.084694.

Cong, N., Piao, S., Chen, A., et al., 2012. Spring vegetation green-up date in China inferred from SPOT NDVI data: a multiple model analysis. Agricultural and Forest Meteorology, 165 , pp.104-113.

Cornelius, C., Leingärtner, A., Hoiss, B., et al., 2013. Phenological response of grassland species to manipulative snowmelt and drought along an altitudinal gradient, Journal of experimental botany, 64(1), pp.241-251.

Dunn, A., Barford, C., Wofsy, S., et al., 2007. A long term record of carbon exchange in a boreal black spruce forest: Means, responses to interannual variability, and decadal trends.

Global Change Biology, 13(3), pp.577-590. 
Huang, X., Hao, X., Wang, W., et al., 2012. Algorithms for cloud removal in MODIS daily snow products. Journal of Glaciology and Geocryology [In Chinese], 34(5), pp.1119-1126.

Inouye, D., 2008. Effects of climate change on phenology, frost damage, and floral abundance of montane wildflowers, Ecology, 2008, 89(2), pp.353-362.

Jönsson, P., and Eklundh, L., 2002. Seasonality extraction by function fitting to time-series of satellite sensor data. Geoscience and Remote Sensing, IEEE Transactions on, 40(8), pp.1824-1832.

Julitta, T., Cremonese, E., Colombo, R., et al., 2013. Snow melt and phenology of a subalpine grassland: analysis through the use of digital camera images, EGU General Assembly Conference Abstracts, (15), pp.3446.

Keller, F., and Körner, C., 2003. The role of photoperiodism in alpine plant development, Journal Information, 35(3), pp.361-368.

Leo, P., IPCC, 2015, Climate Change 2014: Synthesis Report. Contribution of Working Groups I, II and III to the Fifth Assessment Report of the Intergovernmental Panel on Climate Change. Journal of Romance Studies, 4(2), pp.85-88.

Saccone, P., Morin, S., Baptist, F., et al., 2004. The effects of snowpack properties and plant strategies on litter decomposition during winter in subalpine meadows. Plant and soil, 363(1-2), pp.215-229.

Schimel, J., and Bennett, J., 2004. Nitrogen mineralization: challenges of a changing paradigm. Ecology, 85(3), pp.591-602.

Song, Y., Ma, M., and Veroustraete, F., 2010. Comparison and conversion of AVHRR GIMMS and spot vegetation NDVI data in China. International Journal of Remote Sensing, 31(9), pp.2377-2392.
Stow, D., et al., 2003. Variability of the seasonally integrated normalized difference vegetation index across the north slope of Alaska in the 1990s, International Journal of Remote Sensing, 24(5), pp.1111-1117.

Wielgolaski, F., and Inouye, D., 2003. High latitude climates. In: Schwartz, M.D. (Ed.), Phenology: An Integrative Environmental Science. Kluwer, Dordrecht, pp.175-194.

Wipf, S., Rixen, C., and Mulder, C., 2006. Advanced snowmelt causes shift towards positive neighbour interactions in a subarctic tundra community. Global Change Biology, 12(8), pp.1496-1506.

Wu, Y., and Zhu, L., 2008. The response of lake-glacier variations to climate change in Nam Co Catchment, central Tibetan Plateau, during 1970-2000. Journal of Geographic Science, 18(2), pp.177-189.

Zhang, B., Wu, Y., Lei, L., et al., 2013. Monitoring changes of snow cover, lake and vegetation phenology in NamCo Lake basin (Tibetan Plateau) using remote sensing (2000-2009). Journal of Great Lakes Research, 39(2), pp.224-233.

Zhang, G., Xie, H., Yao, T., et al., 2012. Snow cover dynamics of four lake basins over Tibetan Plateau using time series MODIS data (2001-2010). Water Resource Research, 48(10), W10529.

Zhu, L., Xie, M., and Wu, Y., 2010. Quantitative analysis of lake area variations and the influence factors from 1971 to 2004 in the Nam Co basin of the Tibetan Plateau. Chinese Science Bulletin, 55(13), pp.1294-1303. 